Notes \& Tips

\title{
An Amplex Red-based fluorometric and spectrophotometric assay for L-asparaginase using its natural substrate
}

\author{
Christos S. Karamitros a , Jiseok Lim ${ }^{\mathrm{a}, \mathrm{b}}$, Manfred Konrad ${ }^{\mathrm{a}, *}$ \\ a Max Planck Institute for Biophysical Chemistry, D-37077 Goettingen, Germany \\ ${ }^{\mathrm{b}}$ Max Planck Institute for Dynamics and Self-Organization, D-37077 Goettingen, Germany
}

\section{A R T I C L E I N F O}

\section{Article history:}

Received 7 June 2013

Received in revised form 5 September 2013

Accepted 24 September 2013

Available online 7 October 2013

\section{Keywords:}

L-Asparaginase

Leukemia

L-Aspartate oxidase

Coupled enzyme assay

Amplex Red

\begin{abstract}
A B S T R A C T
We report on the development of a sensitive real-time assay for monitoring the activity of L-asparaginase that hydrolyzes L-asparagine to L-aspartate and ammonia. In this method, L-aspartate is oxidized by Laspartate oxidase to iminoaspartate and hydrogen peroxide $\left(\mathrm{H}_{2} \mathrm{O}_{2}\right)$, and in the detection step horseradish peroxidase uses $\mathrm{H}_{2} \mathrm{O}_{2}$ to convert the colorless, nonfluorescent reagent Amplex Red to the red-colored and highly fluorescent product resorufin. The assay was validated in both the absorbance and the fluorescence modes. We show that, due to its high sensitivity and substrate selectivity, this assay can be used to measure enzymatic activity in human serum containing L-asparaginase.
\end{abstract}

(c) 2013 Elsevier Inc. All rights reserved.
The enzyme L-asparaginase (EC 3.5.1.1, L-asparagine amidohydrolase, L-ASNase), ${ }^{1}$ which predominantly occurs in microorganisms and plants, catalyzes the hydrolysis of L-asparagine (L-Asn) to L-aspartic acid (L-Asp) and ammonia [1,2]. Escherichia coli L-ASNase has been used extensively as a therapeutic enzyme in the frontline treatment of lymphoblastic malignancies, such as acute lymphoblastic leukemia (ALL) and non-Hodgkin lymphoma [3,4], since the 1960s. In light of the significance of $\mathrm{L}-\mathrm{ASN}$ ase as a therapeutic protein, various methods have been developed for measuring the enzyme's activity. Those assays can be used in either absorbance mode [5-10] or fluorescence mode $[11,12]$. However, these assays suffer from certain disadvantages that are primarily related to the use of substrate analogs instead of the natural substrate L-Asn [6,7,11,12]. Such assays are not suitable for in vitro evolution of L-asparaginases that aims to select variants showing improved catalytic efficiency and selectivity for the physiological substrate. Moreover, the limited sensitivity of absorption-based spectrophotometric assays $[5-7,9,10]$ is a major handicap to significantly reducing reaction volumes. A noteworthy example of such a case is droplet-based microfluidics, which has emerged as a powerful tool for high-throughput screening in directed protein evolution $[13,14]$. In these experimental setups, the assay volume is minimized to $1 \mathrm{nl}$, to $1 \mathrm{fl}$, scaling down light path lengths to $1 \mu \mathrm{m}$.

\footnotetext{
* Corresponding author. Fax: +495512011074.

E-mail address: mkonrad@gwdg.de (M. Konrad).

1 Abbreviations used: L-ASNase, L-asparaginase; L-Asn, L-asparagine: L-Asp, L-aspartic acid; ALL, acute lymphoblastic leukemia; L-AspOx, L-aspartate oxidase; $\mathrm{H}_{2} \mathrm{O}_{2}$, hydrogen peroxide; HRP, horseradish peroxidase; AR, Amplex Red; FAD, flavin adenine dinucleotide; PBS, phosphate-buffered saline; LOD, limit of detection; NADH, nicotinamide adenine dinucleotide, reduced form; $\mathrm{GDH}$, glutamate dehydrogenase.
}

Here, we report on the development of a novel L-ASNase assay that can be used in either the fluorescence or absorbance mode and relies solely on the use of the physiological substrate L-Asn. In this three-step coupled enzyme system (Fig. 1), L-Asp, which is one of the two products of the L-ASNase reaction, is oxidized by L-aspartate oxidase ( $\mathrm{L}-\mathrm{AspOx})$, resulting in the formation of iminoaspartate and hydrogen peroxide $\left(\mathrm{H}_{2} \mathrm{O}_{2}\right)$; the latter product is used by horseradish peroxidase (HRP) to oxidize the nonfluorescent compound Amplex Red (AR) to resorufin, which exhibits excellent fluorescence as well as absorbance properties.

For establishing and quantitatively evaluating the assay, we cloned and recombinantly produced E. coli L-AspOx [15] (see Fig. S1 in online supplementary material) and periplasmic mature E. coli L-ASNase [16] (Fig. S2), which is the current approved antineoplastic enzyme drug for ALL treatment. The assay was optimized in both the absorbance and fluorescence modes using, for our measurements, a Uvikon 943 double beam UV/VIS (ultraviolet/visible) spectrophotometer and a Jasco FP 8300 spectrofluorometer, respectively. One of the most important criteria to be fulfilled in assays relying on a coupled enzyme system like the one described here is that activity of the auxiliary enzymes always exceeds the enzyme under study. We verified that the rate-determining step of absorption or fluorescence changes in our system was indeed the initial L-ASNase reaction by varying the concentration of L-ASNase. In this context, it is worth underlining that the three enzymes that form this reaction system are characterized by large differences in their kinetic constants, notably in their turnover numbers, with L-AspOx being the least efficient one (steady-state kinetics of L-AspOx is shown in Fig. S3 of the supplementary material) (respective $K_{\mathrm{m}}$ 


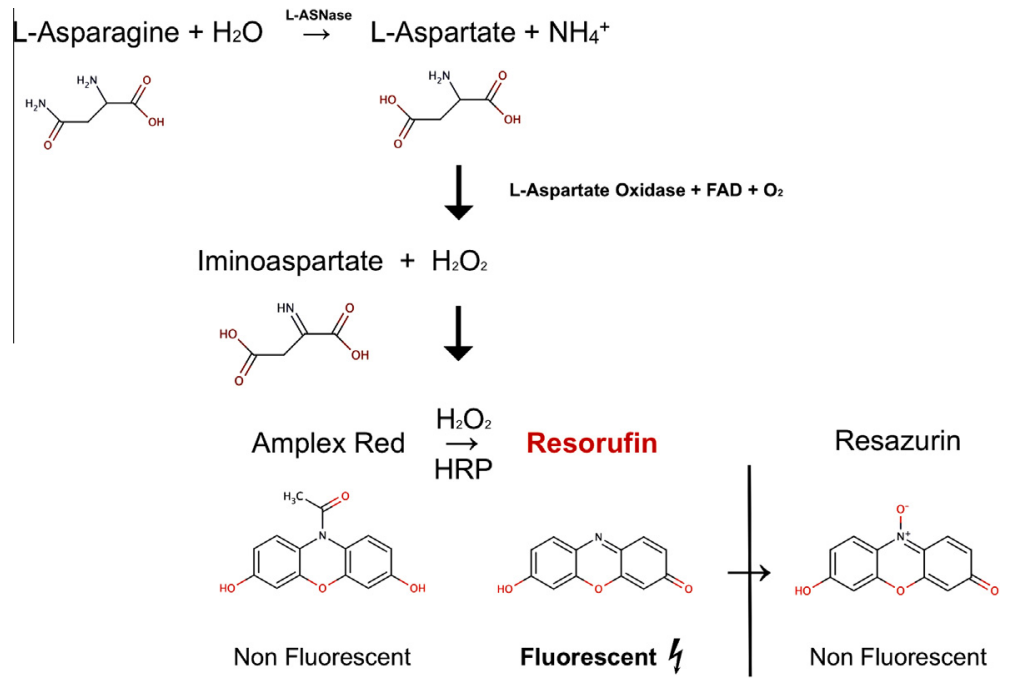

Fig.1. Schematic representation of the AR-dependent L-ASNase coupled-enzyme assay.

and $k_{\text {cat }}$ values: $20 \mu \mathrm{M}$ and $12 \mathrm{~s}^{-1}$ for E. coli L-ASNase; $1.5 \mathrm{mM}$ and $0.5 \mathrm{~s}^{-1}$ for E. coli $\mathrm{L}$-AspOx; $0.1 \mathrm{mM}$ and $560 \mathrm{~s}^{-1}$ for HRP) [17,18].

For standardizing the assay in the fluorescence mode, the final reaction mixture contained 3.5 $\mu \mathrm{M}$ L-AspOx, $10 \mu \mathrm{M}$ flavin adenine dinucleotide (FAD), $100 \mathrm{nM} \mathrm{HRP,} 50 \mu \mathrm{M}$ AR, $4.6 \mathrm{nM}$ L-ASNase ( $16 \mathrm{ng} / 0.1 \mathrm{ml}$ ), and different amounts of $\mathrm{L}$-Asn in a final volume of $100 \mu \mathrm{l}$ using phosphate-buffered saline (PBS) as buffer. Samples were incubated in dark Eppendorf tubes at room temperature. Fluorescence signals were recorded (excitation at $568 \mathrm{~nm}$, emission at $584 \mathrm{~nm}$, bandwidths at $2.5 \mathrm{~nm}$ each) and ultimately corrected by subtracting the control values (no L-Asn) from all samples. Aiming at the optimization of the assay in the fluorescence mode, two critical parameters were further investigated: the concentration of AR in the reaction mixture and the incubation time before recording fluorescence signals. The nonfluorescent AR reacts with $\mathrm{H}_{2} \mathrm{O}_{2}$ in a stoichiometric $1: 1$ ratio, catalyzed by HRP, to form the highly fluorescent product resorufin $[19,20]$. However, as has been shown by others [20], at excess levels of $\mathrm{H}_{2} \mathrm{O}_{2}$ resorufin can be further oxidized to the nonfluorescent compound resazurin. Therefore, the concentration of AR should be kept at least five times higher than that of $\mathrm{H}_{2} \mathrm{O}_{2}$. We tested five different AR concentrations in the range of 10 to $60 \mu \mathrm{M}$ using $1 \mu \mathrm{M} \mathrm{L}$-Asn. Fig. S4 of the supplementary material shows that signals obtained under these conditions are similar and reproducible. In subsequent experiments, we kept AR constant at $50 \mu \mathrm{M}$. We realized that the incubation time prior to activity measurements can be a critical variable that must be optimized in these fluorescent assays. As shown in Fig. S5, fluorescence increases linearly during the first $20 \mathrm{~min}$ and then saturates and remains stable for up to $60 \mathrm{~min}$ after incubation. However, the best signal-to-noise ratio (factor of $\sim 25$ ) was obtained after $30 \mathrm{~min}$ of incubation. Therefore, in all reactions, we incubated the mixture for $30 \mathrm{~min}$ at room temperature before monitoring fluorescence. Alternatively, the reaction can be monitored in a continuous manner for direct kinetic measurements if necessary (Fig. S6). As Fig. 2A shows, the fluorescence signals increase proportionally with the L-ASNase concentration in the range of 0.1 to $4.6 \mathrm{nM}(0.4-$ $16 \mathrm{ng} / 0.1 \mathrm{ml})$. In subsequent kinetic experiments, we used $16 \mathrm{ng}$ of L-ASNase in $0.1-\mathrm{ml}$ reaction mixtures. Importantly, this proportionality also holds in the case of L-ASNase-supplemented human serum samples; therefore, this assay can be used in clinical analyses of L-ASNase activity (Fig. S7). The limit of detection (LOD) of this fluorescent assay was determined to be $100 \mathrm{nM} \mathrm{L}$-Asn based on the standard deviation $(\sigma)$ of the blank samples and the slope $(m)$ of the calibration curve, according to the following equation: $\operatorname{LOD}=(3 \times \sigma) / \mathrm{m}$. Moreover, this concentration could be reliably traced with high reproducibility ( $Z$ ' factor $~ 0.77$; see supplementary material). Fig. 2B demonstrates the linearity of the assay in the concentration range of 0.1 to $10 \mu \mathrm{M}$ L-Asn.
As mentioned above, one of the major advantages of this assay is the fact that it can be used not only in fluorescence mode but also in absorbance mode due to the favorable absorption properties of the final product resorufin showing a maximum at approximately $570 \mathrm{~nm}$ with $\varepsilon=5.4 \times 10^{4} \mathrm{M}^{-1} \mathrm{~cm}^{-1}$ [21]. Similar to optimized conditions for fluorescence detection, absorbance measurements were performed at $25^{\circ} \mathrm{C}$ for a time period of $10 \mathrm{~min}$ in a final volume of $1 \mathrm{ml}$ of PBS buffer containing $3.5 \mu \mathrm{M}$ L-AspOx, $10 \mu \mathrm{M}$ FAD, $100 \mathrm{nM}$ HRP, and $50 \mu \mathrm{M}$ AR. To assess quantitative features and general validity of the new L-ASNase assay, we performed steady-state kinetic analyses to determine characteristic catalytic parameters. First, we determined the level of L-ASNase, up to which the velocity of the reaction remains linear. Fig. $2 \mathrm{C}$ shows that the response is linear in the AR-dependent assay when using 0.68 to $34 \mathrm{nM}(24-1200 \mathrm{ng} / \mathrm{ml}) \mathrm{L}-\mathrm{ASN}$ ase. Based on this result, and to meet conditions required for initial rate measurements, $30 \mathrm{ng}$ of enzyme per milliliter ( $0.85 \mathrm{nM})$ was used for subsequent kinetic experiments covering substrate concentrations in the range of 0 to $15 K_{\mathrm{m}}$. The enzyme followed Michaelis-Menten kinetics (Fig. 2D). Kinetic constants were calculated by nonlinear regression, yielding $K_{\mathrm{m}}=22 \pm 1.2 \mu \mathrm{M}, k_{\text {cat }} \sim 12.1 \pm 0.5 \mathrm{~s}^{-1}$, and $k_{\text {cat }} / K_{\mathrm{m}}=5.5 \times 10^{5} \mathrm{M}^{-1} \mathrm{~s}^{-1}$.

To validate this AR-dependent assay, we compared our data with kinetic constants reported before by making use of the nicotinamide adenine dinucleotide (NADH)-dependent assay [9]. Briefly, the produced ammonia serves as substrate for glutamate dehydrogenase (GDH) that converts $\alpha$-ketoglutarate to L-glutamic acid (L-Glu) with simultaneous oxidation of NADH. The disappearance of NADH is reflected by a decrease in absorption at $340 \mathrm{~nm}$, with $\varepsilon=6.22 \times 10^{3}$ $\mathrm{M}^{-1} \mathrm{~cm}^{-1}$ (at $\mathrm{pH} 7.5$ ). Thus, the oxidation of $\mathrm{NADH}$ is directly proportional to the amount of ammonium generated by L-ASNase activity. Similar to the L-AspOx-dependent spectrophotometric assay, reactions were performed at $25^{\circ} \mathrm{C}$ in a final volume of $1 \mathrm{ml}$ of PBS containing $0.25 \mathrm{mM} \mathrm{NADH}, 0.25 \mathrm{mM} \alpha$-ketoglutarate, and $35 \mathrm{nM} \mathrm{GDH}$ from bovine liver. The L-ASNase concentration was $7 \mathrm{nM}(\sim 250 \mathrm{ng} /$ $\mathrm{ml}$ ). Fig. S6 shows the resulting Michaelis-Menten plot. The calculated kinetic constants are $21 \pm 1.5 \mu \mathrm{M}$ for $K_{\mathrm{m}}, 11.5 \pm 0.4 \mathrm{~s}^{-1}$ for $k_{\text {cat }}$, and $5.4 \times 10^{5} \mathrm{M}^{-1} \mathrm{~s}^{-1}$ for $k_{\mathrm{cat}} / K_{\mathrm{m}}$. The values obtained by these two assays (summarized in Table S1 of the supplementary material) are in excellent agreement, indicating that the newly developed fluorescence assay is a reliable and more sensitive alternative to the NADHdependent assay, requiring approximately 10 -fold less L-ASNase.

In summary, here we reported on the development of a highly sensitive assay for measurement of L-ASNase activity. This L-ASNase assay comprises three coupled enzymatic reactions. It relies on the use of L-AspOx in the second reaction step, which generates $\mathrm{H}_{2} \mathrm{O}_{2}$ that, in the presence of HRP, oxidizes the nonfluorescent AR agent to the highly 

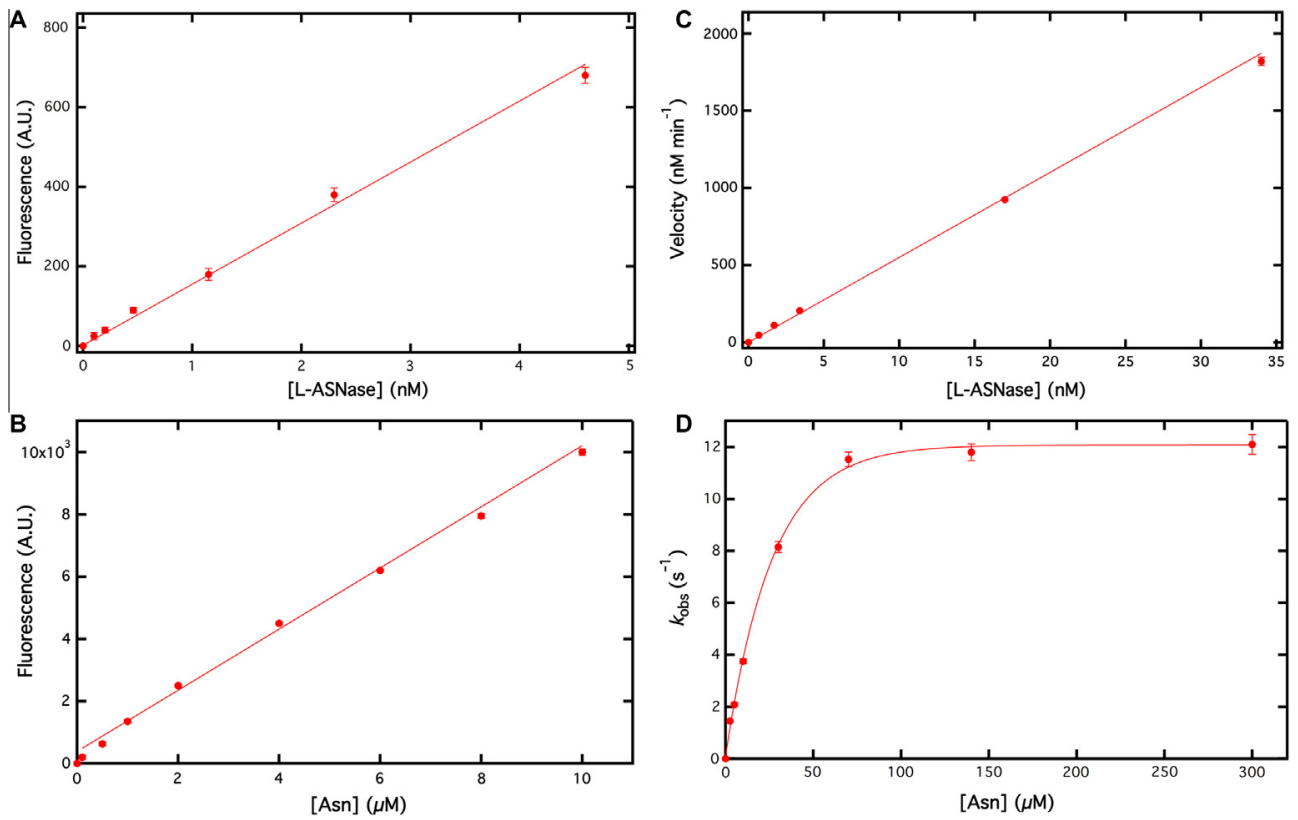

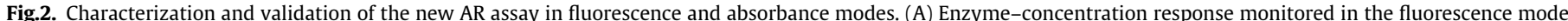

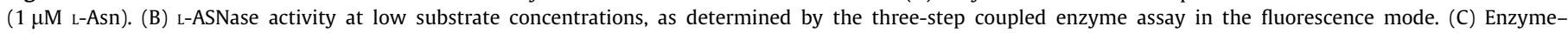

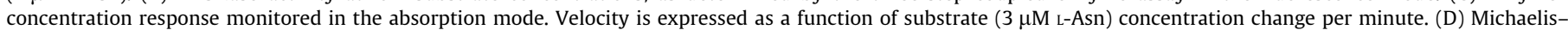

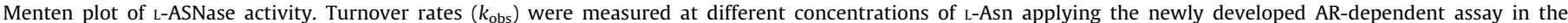
absorbance mode. All data points are the means \pm standard deviations of triplicate measurements.

red fluorescent resorufin product. Advantages of this assay are that it is homogeneous, allowing adjustment of the assay conditions, such as temperature and buffer composition, according to specific requirements, and that it can in principle be applied in both the absorbance and fluorescence modes. Taking advantage of resorufin's excellent fluorescence and absorption properties, we showed that this assay can reliably be used to detect low amounts of $\mathrm{L}$-Asn and monitor low levels of $\mathrm{L}-$ ASNase activity not only when purified enzyme is used but also when its activity is to be determined in human serum. Notably, the enzyme can be kinetically characterized using its natural substrate and requiring 10 -fold less protein compared with other widely used assays.

\section{Acknowledgments}

This work was supported by the Max Planck Society and by a National Research Foundation of Korea fellowship to J.L. (NRF2011-357-D00011). We thank Ursula Welscher-Altschäffel for technical assistance with protein preparation and thank Claudia Höbartner for helpful comments on the manuscript.

\section{Appendix A. Supplementary data}

Supplementary data associated with this article can be found, in the online version, at http://dx.doi.org/10.1016/j.ab.2013.09.028.

\section{References}

[1] K. Aghaiypour, A. Wlodawer, J. Lubkowski, Structural basis for the activity and substrate specificity of Erwinia chrysanthemi L-asparaginase, Biochemistry 40 (2001) 5655-5664.

[2] M. Kozak, D. Borek, R. Janowski, M. Jaskolski, Crystallization and preliminary crystallographic studies of five crystal forms of Escherichia coli L-asparaginase II (Asp90Glu mutant), Acta Crystallogr. D 58 (2002) 130-132.

[3] A.L. Stecher, P.M. de Deus, I. Polikarpov, J. Abrahao-Neto, Stability of L-asparaginase: an enzyme used in leukemia treatment, Pharm. Acta Helv. 74 (1999) 1-9.

[4] M. Duval, S. Suciu, A. Ferster, X. Rialland, B. Nelken, P. Lutz, Y. Benoit, A. Robert, A.M. Manel, E. Vilmer, J. Otten, N. Philippe, Comparison of Escherichia coliasparaginase with Erwinia-asparaginase in the treatment of childhood lymphoid malignancies: results of a randomized european organization for research and treatment of cancer-children's leukemia group phase 3 trial, Blood 99 (2002) 2734-2739.
[5] H.A. Campbell, L.T. Mashburn, E.A. Boyse, L.J. Old, Two L-asparaginases from Escherichia coli B: their separation, purification, and antitumor activity, Biochemistry 6 (1967) 721-730.

[6] D. Cooney, R. Handschumacher, L-Asparaginase and L-asparagine metabolism, Annu. Rev. Pharmacol. 10 (1970) 421-440.

[7] Y.Z. Frohwein, M. Friedman, J. Reizer, N. Grossowicz, Sensitive and rapid assay for L-asparaginase, Nat. New Biol. 230 (1971) 158-159.

[8] C. Lanvers, J.P.V. Pinheiro, G. Hempel, G. Wuerthwein, J. Boos, Analytical validation of a microplate reader-based method for the therapeutic drug monitoring of $\mathrm{L}$ asparaginase in human serum, Anal. Biochem. 309 (2002) 117-126.

[9] V.M. Balcão, C. Mateo, R. Fernandez-Lafuente, F.X. Malcata, J.M. Guisa, Structural and functional stabilization of L-asparaginase via multisubunit immobilization onto highly activated supports, Biotechnol. Prog. 17 (2001) 537-542.

[10] A. Credali, M. Garcia-Calderon, S. Dam, J. Perry, A. Diaz-Quintana, M. Parniske, T.L. Wang, J. Stougaard, J.M. Vega, A.J. Marquez, The $\mathrm{K}^{+}$-dependent asparaginase, NSE1, is crucial for plant growth and seed production in Lotus japonicus, Plant Cell Physiol. 54 (2013) 107-118.

[11] I.T. Mononen, V.M. Kaartinen, J.C. Williams, A fluorometric assay for glycosylasparaginase activity and detection of aspartylglycosaminuria, Anal. Biochem. 208 (1993) 372-374.

[12] P. Ylikangas, I. Mononen, A fluorometric assay for L-asparaginase activity and monitoring of L-asparaginase therapy, Anal. Biochem. 280 (2000) 42-45.

[13] J.C. Baret, O.J. Miller, V. Taly, M. Ryckelynck, A. El-Harrak, L. Frenz, C. Rick, M.L. Samuels, J.B. Hutchison, J.J. Agresti, D.R. Link, D.A. Weitzc, A.D. Griffiths, Fluorescence-activated droplet sorting (FADS): efficient microfluidic cell sorting based on enzymatic activity, Lab Chip 9 (2009) 1850-1858.

[14] J. Lim, P. Gruner, M. Konrad, J.C. Baret, Micro-optical lens array for fluorescence detection in droplet-based microfluidics, Lab Chip 13 (2013) 1472-1475.

[15] R. Flachmann, N. Kunz, J. Seifert, M. Gutlich, F.J. Wientjes, A. Laufer, H.G. Gassen, Molecular biology of pyridine nucleotide biosynthesis in Escherichia coli, Eur. J. Biochem. 175 (1988) 221-228.

[16] D.T. Bonthron, L-Asparaginase II of Escherichia coli K-12: cloning, mapping, and sequencing of the ansB gene, Gene 91 (1990) 101-105.

[17] G. Tedeschi, S. Ronchi, T. Simonic, C. Treu, A. Mattevi, A. Negri, Probing the active site of L-aspartate oxidase by site-directed mutagenesis: role of basic residues in fumarate reduction, Biochemistry 40 (2001) 4738-4744.

[18] B.D. Howes, N.C. Brissett, W.A. Doyle, A.T. Smith, G. Smulevich, Spectroscopic and kinetic properties of the horseradish peroxidase mutant T171S: evidence for selective effects on the reduced state of the enzyme, FEBS J. 272 (2005) 5514-5521.

[19] J.G. Mohanty, J.S. Jaffe, E.S. Schulman, D.G. Raible, A highly sensitive fluorescent micro-assay of $\mathrm{H}_{2} \mathrm{O}_{2}$ release from activated human leukocytes using a dihydroxyphenoxazine derivative, J. Immunol. Methods 202 (1997) 133-141.

[20] A. Zhu, R. Romero, H.R. Petty, A sensitive fluorimetric assay for pyruvate, Anal. Biochem. 396 (2010) 146-151.

[21] M. Zhou, Z. Diwu, N. Panchuk-Voloshina, R.P. Haugland, A stable nonfluorescent derivative of resorufin for the fluorometric determination of trace hydrogen peroxide: applications in detecting the activity of phagocyte NADPH oxidase and other oxidases, Anal. Biochem. 253 (1997) 162168. 
